\title{
Would Nonconsensual Criminal Neurorehabilitation Express a more Degrading Attitude Towards Offenders than Consensual Criminal Neurorehabilitation?
}

\author{
Jukka Varelius iD \\ Received: 18 June 2020 / Accepted: 29 October 2020 / Published online: 6 November 2020 \\ (C) The Author(s) 2020
}

\begin{abstract}
It has been proposed that reoffending could be reduced by manipulating the neural underpinnings of offenders' criminogenic mental features with what have been called neurocorrectives. The legitimacy of such use of neurotechnology - criminal neurorehabilitation, as the use is called - is usually seen to presuppose valid consent by the offenders subjected to it. According to a central criticism of nonconsensual criminal neurorehabilitation, nonconsensual use of neurocorrectives would express a degrading attitude towards offenders. In this article, I consider this criticism of nonconsensual criminal neurorehabilitation. By using cases of autonomous persons who lead a subservient existence as an example, I propose that nonconsensual criminal neurorehabilitation need not express a more degrading attitude towards offenders than consensual criminal neurorehabilitation. The argument of this article does not show that nonconsensual criminal neurorehabilitation is morally or legally acceptable. Yet, in view of the argument, criticizing nonconsensual criminal neurorehabilitation for expressing a degrading attitude towards offenders is not compatible with simultaneously endorsing consensual criminal neurorehabilitation.
\end{abstract}

Keywords Autonomy · Consent - Criminal Neurorehabilitation $\cdot$ Neurotechnology $\cdot$ Offender . Recidivism

J. Varelius $(\bowtie)$

Department of Philosophy, Contemporary History, and Political Science, FIN-20014 University of Turku, Turku, Finland e-mail: jukka.varelius@utu.fi

\section{Introduction}

The idea of improving the criminal justice system by neuroscientific means is gathering increasing attention. In one of the scenarios presented, reoffending could be reduced by manipulating the neural underpinnings of offenders' criminogenic mental features with what have been called neurocorrectives (see e.g. [1-4]). ${ }^{1}$ The legitimacy of such use of neurotechnology - criminal neurorehabilitation, as the use is called - is usually seen to presuppose valid consent by the offenders subjected to it (see e.g. [7] and below). According to a central criticism of nonconsensual criminal neurorehabilitation, nonconsensual neurocorrectives would express a degrading attitude towards offenders (see e.g. [8-10]). ${ }^{2}$ In this article, I consider the just described criticism of nonconsensual criminal neurorehabilitation.

I begin by formulating the main starting points of the consideration. By using cases of autonomous persons who lead a subservient existence as an example, I propose that nonconsensual criminal neurorehabilitation need not express a more degrading attitude towards offenders than consensual criminal neurorehabilitation.

\footnotetext{
$\overline{{ }^{1} \text { Besides its possible uses in criminal rehabilitation, it has also been }}$ proposed that neurotechnology could help in assessing defendants' culpability and determining the reliability of testimonies, for example (see also e.g. [5, 6]).

${ }^{2}$ Some authors do argue for nonconsensual criminal neurorehabilitation (see e.g. [11-13]). As regards the concern that nonconsensual criminal neurorehabilitation would convey a degrading attitude towards offenders, Douglas [11] proposes that treating an offender's moral motivations as deficient can be warranted, may ultimately promote an offender's wellbeing, and need not be more disrespectful towards an offender than incarceration.
} 
After that, I consider three possible objections to the proposal. Finally, I conclude by briefly clarifying the purported import of the argument of this article. I will not here consider such questions as how, precisely, a criminal justice system ought to treat offenders or exactly how degrading treatment an offender ought to endure. The focus below is only on the question whether nonconsensual criminal neurorehabilitation would necessarily convey a more degrading attitude toward offenders than its consensual counterpart.

\section{Central Starting Points}

According to the Code of Laws of the United States (§ 3582(a) [14]), imprisonment decisions shall be made "recognizing that imprisonment is not an appropriate means of promoting correction and rehabilitation." The European Court of Human Rights, for another example, has held repeatedly that all prisoners must be offered the possibility of rehabilitation (e.g. Vinter and others $v$. The United Kingdom [15]; Harakchiev and Tolumov v. Bulgaria [16], see also e.g. [17]). Accordingly, criminal rehabilitation programs are quite commonly arranged as supplements or alternatives to traditional criminal punishments like incarceration. The programs typically aim to steer offenders towards a law-abiding life by employing such means as cognitive behavioral therapy, (moral) education, and work training (see e.g. [2, 4, 18, 19]).

Relevantly from the viewpoint of using neurotechnology in criminal rehabilitation, it has been proposed that neurointerventions could mitigate undue aggression and motivation to harm others and improve cognitive functioning, self-control, and ability to cope with stress, for instance. This would be based on manipulation of the neural underpinnings of pertinent cognitive and motivational features with neurochemical means, surgical methods, electricity, or ultrasound. (See e.g. [1, 20, 21]). Some authors question the prospect of there (soon) being sufficiently safe and effective neurointerventions of the kind (see e.g. [22]). Instead of assessing the latest results of neuroscience or attempting to predict its future, I now just assume that the prospect is realistic enough to warrant the attention it receives here. ${ }^{3}$

\footnotetext{
${ }^{3}$ Some jurisdictions already practice criminal neurorehabilitation in the form of chemical castration, for instance (see also e.g. [8, 23]). For a defense of the usefulness of discussing even as yet hypothetical neurocorrectives, see e.g. Ryberg [3].
}

A criminal rehabilitation program is consensual when an offender is allowed autonomously to choose whether or not she undergoes it. An offender's choice about her participation in criminal rehabilitation is commonly deemed autonomous when the choice is intentional, based on adequate understanding of the nature of the rehabilitation program in question and its effects on her, and made without controlling influences that determine her decision (see e.g. [24, 25]). Criminal rehabilitation is nonconsensual when an offender is subjected to it independently of whether or not she consents to undergo it (see also e.g. [26], 119). ${ }^{4}$

Many scholars too, not only legislators and practitioners, welcome consensual criminal rehabilitation, even when it would use neuroscientific means. Shaw [10], for instance, writes as follows:

Many punishment theorists believe that rehabilitation, potentially through neurointerventions, can be one of the legitimate aims of the criminal justice system. Nevertheless, such theorists typically insist that neurointerventions should only be offered to offenders on a voluntary basis.

Accordingly, critics of criminal neurorehabilitation typically focus on nonconsensual criminal neurorehabilitation. For instance, Bublitz's criticism of criminal neurorehabilitation is aimed at "mandatory rehabilitation" ([8], 290). According to Shaw [10], "neurointerventions should never be ordered as a compulsory part of a criminal sentence." And Kirchmair [9], for a yet further instance, critiques "the coercive use of neurocorrectives." As was also suggested, a central criticism of nonconsensual criminal neurorehabilitation is that nonconsensual neurocorrectives would express a degrading attitude towards offenders.

Why would nonconsensual criminal neurorehabilitation convey a degrading attitude towards offenders? Bublitz [8], for example, writes as follows:

Respecting a person as a subject (her agency) implies respecting her as a self-controlling being.

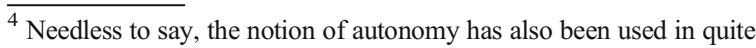
different senses than the one just described (see e.g. [27, 28]; and below). Yet, as it is the sense of autonomy commonly referred to in this connection, I here employ the above-characterized sense of the notion. Moreover, I here focus on offenders who meet the criteria of autonomy. Nonconsensual criminal neurorehabilitation of offenders who do not meet the criteria of autonomy merits its own discussion, which is now postponed to future work.
} 
... Altering the mental machinery at the neurophysiological level alone ${ }^{[5]}$ is objectifying and disrespectful of the targeted person as a rational and self-controlling being and, thereby, of her as an autonomous subject. ${ }^{[6]}$

Kirchmair [9], for another instance, maintains that:

coercive neurocorrectives envision making morally deficient criminal offenders morally fit against their will. ${ }^{[7]}$ Such morally deficient criminal offenders are thus not perceived as autonomous human beings who can change by themselves, but as nonautonomous, deficient beings who must be fixed.

Consequently, Kirchmair argues, nonconsensual criminal neurorehabilitation conflicts with Article 3 of the European Convention of Human Rights according to which "[n]o one shall be subjected to torture or to inhuman or degrading treatment or punishment" [29]. And Shaw [10], for a yet further example, focuses on the message conveyed by the invasion of integrity that she sees nonconsensual criminal neurorehabilitation to involve:

Invading the profoundly intimate sphere of the offender's mind and body, depriving a person of control over herself, seems to convey the objectionable message that this person is fundamentally inferior and needs to be remoulded.

\footnotetext{
$\overline{5}$ Neurofeedback, for instance, employs the rational capacities of the individual undergoing it and could also have uses in criminal rehabilitation. As an offender subjected to criminal neurorehabilitation independently of her consent need not necessarily object to the rehabilitation, such methods as neurofeedback could assumedly sometimes be employed in nonconsensual criminal neurorehabilitation too. Yet, as Bublitz apparently does here, a critic of nonconsensual criminal neurorehabilitation can focus only on neurocorrectives that would alter offenders' mental machinery at the neurophysiological level alone.

${ }^{6}$ While Bublitz also refers to other reasons against nonconsensual neurocorrectives (see [8], 298-303), he would appear to deem the attitude that nonconsensual criminal neurorehabilitation would express towards offenders as the central degrading feature of such rehabilitation.

${ }^{7}$ As it would nevertheless be administered independently of their will, even nonconsensual criminal neurorehabilitation that would not be against the will of the offenders subjected to it could be seen to express a (somewhat) degrading attitude towards them. Yet, a critic of nonconsensual criminal neurorehabilitation can want to focus on neurorehabilitation that would be against the will of the offenders subjected to them.
}

The criticisms of nonconsensual neurocorrectives presented by Bublitz, Kirchmair, and Shaw are, I take it, sufficiently similar to each other to count as versions of the same basic objection. ${ }^{8}$

I assume that the central idea of the objection can, without manhandling it too much, be formulated as follows: Subjecting an autonomous offender to nonconsensual criminal neurorehabilitation would express a degrading attitude towards her because altering her mental features without her autonomous consent would deny the offender the status of an autonomous agent and thereby treat her as an inferior, deficient being to be remolded. Its proponents need not maintain that the line of criticism shows nonconsensual criminal neurorehabilitation to be overall morally or legally unjustifiable. They may just argue that the degrading attitude that nonconsensual neurocorrectives (in their view) would convey towards offenders makes nonconsensual criminal neurorehabilitation significantly harder to justify than, say, such traditional means of treating offenders as incarceration.

That nonconsensual criminal neurorehabilitation would express a degrading attitude towards offenders is evidently not the only problem faced by nonconsensual neurocorrectives (see e.g. [1, 3]). Yet, an exhaustive analysis of potential ways of developing the criminal justice system presupposes addressing the claimed degradingness of nonconsensual use of neurocorrectives. As considering it also provides enough material for one article, I take it that my focusing on the particular criticism of nonconsensual criminal neurorehabilitation here is warranted.

\section{Subservience, Degradingness, and Consent}

So far, the kind of subservience to which the argument of this article relates would appear to have received most attention in connection with marital life. To borrow a potentially helpful example from that context, consider the case of Anna, a woman utterly devoted to serving

\footnotetext{
${ }^{8}$ While some proponents of the line of criticism focus also on the humiliation that would actually be experienced by offenders subjected to nonconsensual neurocorrectives, concentration on the attitude that would be expressed towards offenders by subjecting them to nonconsensual criminal neurorehabilitation appears more common. And Shaw [10], for instance, emphasizes that only the expression of a degrading attitude is always a characteristic of nonconsensual neurocorrectives.
} 
her husband. Anna wears the clothes he prefers, invites the guests he wants to entertain, and makes love whenever he is in the mood. She willingly moves to a new city in order for him to have a more attractive job, counting her own work, friendships, and geographical preferences insignificant by comparison. To the extent that she forms her own values and goals, she counts them as less important than those of his. Anna is convinced that the proper role for a wife is to serve her husband. ${ }^{9}$

In connection with welcoming the couple to their new neighborhood, the chair of the local residents' association, Ben, takes note of Anna's subservience. As it happens, Ben is also the president of Equal Spouses, an organization promoting equality in marital life. Being concerned about Anna's submissiveness, Ben subsequently informs her of the counseling programs arranged by Equal Spouses. Although some people consider it degrading to be taught by others how to arrange one's marital life, the programs have been quite successful in teaching subservient wives and husbands to respect themselves and to hold on to their rights. Having learned about the programs, her friends try to persuade Anna to participate in the counseling. However, out of her submissiveness to her husband, she declines. Her friends decide that they must respect Anna's autonomy and refrain from pressuring her to change her mind. Consequently, Anna continues to lead her subservient existence. ${ }^{10}$

Anna's subservience can apparently be intentional. A person like Anna can assumedly also understand both what she is doing in submitting to her husband and how her subservient behavior affects her existence. And Anna's subservience need not necessarily be based on any controlling influence that determines her behavior. The same applies to her subservient refusal to take part in the counseling program proposed to her. The refusal can be intentional, it can be based on Anna's adequately understanding the nature of the program and its potential effects on her life, and it need not necessarily be grounded on her being, say, pressured or manipulated to refuse it. Hence, both Anna's behavior towards her husband

\footnotetext{
9 The example is borrowed from Hill [30].

${ }^{10}$ Programs such as those arranged by Equal Spouses might be less likely to employ neuroscientific means (that alter people's mental life at the neurophysiological level alone) than criminal rehabilitation. Yet, that does not undermine the point I am trying to make with the example (see below).
}

and her refusal to take part in the counseling program can meet the criteria of autonomy described above. ${ }^{11}$

Yet, Anna is still being denied - by herself and by her spouse, at least - the status of an autonomous agent and perceived as inferior to her husband, as a deficient being to be molded as he wishes. Accordingly, Anna's subservience can be deemed degrading despite its being consensual. This intuition could be supported by maintaining, for example, that Anna's submissiveness conflicts with the kind of Kantian criteria of autonomy that require one to always respect humanity, whether in one's own person or in that of another, equally (see e.g. [30]). Or it could be maintained that Anna's submissive behavior is incompatible with her consentinsensitive duty to respect herself and to not let others treat her degradingly (see e.g. [31]), ${ }^{12}$ with the duty she has to care for her own welfare (see e.g. [32]), with the duties she has to her other 'perspectives' (see [33 $]^{13}$; and also e.g. [34]) or to her future selves (see e.g. [35]), for further instances.

Compare Anna's case with another potentially helpful example from the sphere of marital life, the case of Charles. Charles wears the clothes his wife prefers, invites the guests she wants to entertain, etc. Indeed, Charles's case is relevantly similar to Anna's with one exception. When his friends persuade Charles to take part in a counseling program arranged by Equal Spouses, Charles finds himself torn between submitting to his wife and doing what his friends tell him to do. Ultimately, his friends manage to pressure Charles to participate in the program. Yet, as submissive as he is to his wife, Charles considers this to be against his will. However, the program works quite well and, after a while, Charles starts to feel different about many things in his life. Once the program is over, he no longer denies himself the status of an autonomous agent nor perceives

\footnotetext{
${ }^{11}$ To clarify, I am not saying that all subservient spouses are autonomous, but that some of them can, and do, meet the criteria of autonomy now in question. And Anna is now assumed to belong to those who meet the criteria of autonomy.

${ }^{12}$ Using exploitation as an example, Schaber [31] elucidates the notion of a consent-insensitive duty as follows: "Valid consent cannot release others form consent-insensitive duties because it cannot eliminate the wrong-making property of the acts in question, for instance, exploiting someone. If one exploits another person one commits a wrong by wronging the victim, even if the victim has consented to it."

${ }^{13}$ Schofield [33] characterizes a perspective as "a point of view from which one perceives, or feels emotions, or has sensations, or judges a proposition to be true, or wills some particular action, and so on" and maintains that one's possession of such perspectives gives rise to moral obligations to oneself.
} 
himself as inferior to his wife, as a deficient being to be molded as she wishes.

While Anna made an autonomous choice about taking part in the counseling proposed to her, Charles's choice to participate in the counseling program he attended did not meet the criteria of autonomy now in question. Instead, as explained, Charles participated in the program against his will, because of the tough love his friends practiced on him. However, it would seem that in pressuring him to attend the counseling program Charles's friends did not express a more degrading attitude towards him than did Anna's friends convey towards her by respecting her choice to refuse the counseling program offered to her. Indeed, Charles's friends arguably acted even less degradingly towards him than Anna's friends acted towards her, despite the fact that only Anna was allowed to make an autonomous choice about participation in the counseling. After all, Anna was permitted to ground her choice on her subservience and, unlike Charles who now leads a life in which he receives the respect he is due, Anna continues her demeaning submissive existence. Even if Charles's counseling had turned out to be less successful than it was and even if Anna had eventually found a way out of her subservience, Charles's friends arguably expressed a less degrading attitude towards him than Anna's friends conveyed towards her. That is so, because by respecting her subservient choice to continue her demeaning existence, Anna's friends conveyed that they are not as concerned about whether or not her life is degrading as Charles's friends are about whether or not his existence is degrading. ${ }^{14}$

\section{Subservience, Degradingness, and Consensual and Nonconsensual Criminal Neurorehabilitation}

The kind of subservience the cases of Anna and Charles exemplify apparently occurs in other contexts besides marital life. ${ }^{15}$ To see how such subservience could figure in connection with criminal neurorehabilitation,

\footnotetext{
${ }^{14}$ Whether or not it conveys a degrading attitude towards its object is not the only question relevant to assessing the moral justifiability of the kind of behavior in which the friends of Anna and Charles engaged. Given that the other pertinent questions cannot be examined here, I now refrain from judging whether the behavior was overall morally acceptable. For pertinent discussion, see e.g. Cholbi [36] and Groll [37].

${ }^{15}$ For discussion on (a kind of) subservience within occupational life, see e.g. Rocha [38].
}

consider the cases of Diana and Ethan. Young people growing up in their neighborhood often end up in gangs that engage in violence and crime. That is what happened in the cases of Diana and Ethan too. Subservient as she is, Diana submits to the leaders of her gang; she wears the clothes they tell her to wear (the colors), spends her days as they wish, etc. As a result of her submissiveness, Diana also became a recidivist. Having just been convicted again, she is offered the possibility of taking part in criminal neurorehabilitation. However, out of her subservience to the leaders of her gang, Diana refuses the offer and continues to lead her submissive existence.

Diana's behavior is intentional, she acts knowingly, and she makes her choices without controlling influences that would determine them. Accordingly, her behavior qualifies as autonomous in the sense now focused on. ${ }^{16}$ Nevertheless, like Diana herself, the leaders of her gang deny her the status of an autonomous agent and perceive her as inferior to them, as a deficient being to be molded as they wish. Hence, like Anna's submissiveness, Diana's subservience is arguably degrading, despite being consensual. The intuition could, again, be supported by maintaining that Diana's submissiveness conflicts with the kind of Kantian criteria of autonomy that require one to always respect humanity, whether in one's own person or in that of another, equally (see e.g. [30]). Or it could be maintained that, correspondingly to that of Anna's, Diana's submissive behavior is incompatible with the duty Diana has to care for her own welfare (see e.g. [32]), with the duties she has to her other 'perspectives' (see [33]; and also e.g. [34]) or to her future selves (see e.g. [35]), or with her consent-insensitive duty to respect herself and to not let others treat her degradingly (see e.g. [31]), for further examples.

Compare Diana's case with that of Ethan. Subservient as he is, Ethan defers to the leaders of his gang; he

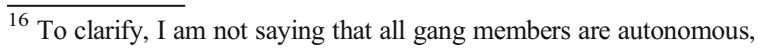
but that some of them can, and do, meet the criteria of autonomy now in question and Diana is now assumed to belong to those who meet the criteria of autonomy. Also, I am not claiming that the relationships between friends and those between the criminal justice system and offenders are, or should be, similar to each other. The comparison between the cases of Anna and Charles was presented just to introduce the notion of subservience focused on here. In this section, the central comparison is that between the cases of Diana and Ethan (see below). Ethan's case differs from that of Charles in that the criminal justice system coerced Ethan to undergo criminal neurorehabilitation whereas Charles's friends just pressured him to participate in the counseling, for instance.
} 
wears the clothes they tell him to wear, spends his days as they wish, and became a recidivist. Indeed, Ethan's case is otherwise relevantly similar to Diana's, except that after his latest conviction Ethan was subjected to nonconsensual criminal neurorehabilitation. The rehabilitation he underwent improved his cognitive functioning, self-control, and ability to cope with stress and mitigated his undue aggression and motivation to harm others. With improved self-control and better ability to endure stress, Ethan is less likely to be affected by the bad influence of others and more able to resist the temptation of alcohol and drugs, the use of which has taken much of his time so far. With better cognitive abilities, Ethan is more able to complete his interrupted education and to acquire a legitimate job to support himself. And as less aggressive and less motivated to harm others, he is more likely to stay out of trouble and also more able to develop meaningful relationships with others, for instance. Accordingly, besides making lawabiding life easier for him, and related to it, the rehabilitation also made Ethan significantly more able to respect himself. ${ }^{17}$ As a result, Ethan rejected his conception of himself as inferior to the leaders of his gang and no longer sees himself as a deficient being to be molded as they wish.

Now, Diana did not undergo the degradingness that being subjected to nonconsensual neurocorrectives is now perceived to involve (see section 2 above). However, although Ethan's criminal neurorehabilitation was nonconsensual, subjecting him to it would not seem to express a more degrading attitude towards him than allowing Diana subserviently to refuse the criminal neurorehabilitation proposed to her conveys towards her. Indeed, it would seem that, overall, allowing a person like Diana subserviently to refuse criminal neurorehabilitation would amount to expressing an even more degrading attitude towards her than neurorehabilitating an offender like Ethan independently of his will would convey towards him. ${ }^{18}$ After all, Diana was allowed to ground her refusal of the rehabilitation on her subservient attitudes and, unlike Ethan who

\footnotetext{
${ }^{17}$ Indeed, insofar as self-respect is an essential element of a worthwhile existence (see e.g. [39], 386), the goal of steering offenders towards a law-abiding life and that of promoting their self-respect are arguably closely intertwined with each other, to say the least.

${ }^{18}$ Someone might consider it relevant that subjecting an offender to nonconsensual criminal neurorehabilitation requires more activity from the criminal justice system than allowing an offender to refuse criminal neurorehabilitation. Yet, as attested to by the cases of Diana and Ethan, how degrading an attitude a behavior expresses need not depend on how much activity the behavior requires (see also e.g. [40]).
}

now leads a law-abiding life in which he receives the respect he is due, Diana continues to lead a degrading submissive and criminal existence. ${ }^{19}$ Even if Ethan's criminal neurorehabilitation had turned out to be less successful than it was and even if Diana had eventually found a way to overcome her subservience, subjecting Ethan to the rehabilitation arguably expressed a less degrading attitude towards him than allowing Diana subserviently to refuse the criminal neurorehabilitation proposed to her conveyed towards her. That is so, because by respecting her subservient choice to continue her demeaning criminal existence, the criminal justice system expressed that it is not as concerned about whether or not Diana leads a degrading criminal existence as the criminal justice system that subjected Ethan to criminal neurorehabilitation independently of his will is about whether or not he leads a degrading criminal life.

True, all offenders are unlikely to be subservient; perhaps many of them are not. Yet, subservience is evidently also not the only possible degrading feature of the life of a criminal. In view of pertinent studies, the life of a criminal is often characterized by such features as severe economic difficulties, negative employment prospects, substance abuse, significant problems in (personal) relationships, mental disorder, and threat of victimization (see e.g. [41-45]). Besides being criminogenic, such difficulties are, as proposed, also likely to undermine the self-respect of the people suffering from them (see also e.g. [46-48]). And others apparently also often treat persons suffering from such difficulties as inferior, deficient beings to be fixed. Hence, while some differences may exist between, say, white- and blue-collar crimes in this respect, the lives of criminals would appear to be significantly more likely to be degrading than those of people in general. ${ }^{20}$

\footnotetext{
${ }^{19}$ Whether an offender's choice about taking part in criminal neurorehabilitation would be based on subservience could sometimes be difficult to determine. Yet, the problem faced here need not be more difficult than are those confronted in connection with determining such factors often deemed relevant to how the criminal justice system should treat offenders as whether an offender intended to cause more serious harm than actually resulted from her wrongdoing, whether his remorse for his crime is genuine, etc.

${ }^{20}$ Sometimes the life of a criminal is presented as honorable (see e.g. [49]). Yet, the validity of such portrayals is often unclear and they are hardly representative of lives of criminals in general. Indeed, may people would appear to deem the very engagement in criminal activity quite demeaning. Although few of us, if any, are entirely safe from such predicaments as those listed above, as proposed, offenders are plausibly among those especially likely to suffer from them.
} 
An offender could evidently also refuse criminal neurorehabilitation for some other reason than for being subservient. She might find law-abiding life too humdrum and ordinary, plan to do the one big job that sets her for the rest of her life, or just want to see how much she could get away with as a criminal. Yet, whatever the reason behind it would be - and even if the reason were not as degrading as it was in Diana's case, - an offender's refusal to undergo the criminal neurorehabilitation proposed to her could have as demeaning consequences as it has in Diana's case, consequences that would not occur were she not allowed to decide about her rehabilitation by herself. ${ }^{21}$ Accordingly, respecting an offender's decision to refuse the criminal neurorehabilitation proposed to him could arguably express an even more degrading attitude towards him than subjecting him to nonconsensual criminal neurorehabilitation. Again, by respecting the offender's choice a criminal justice system would convey that it is not as concerned about whether or not the offender leads a degrading criminal existence as is a criminal justice system that would subject him to nonconsensual criminal neurorehabilitation. Hence, the above considerations point to a more general problem for the criticism of nonconsensual criminal neurorehabilitation now assessed than the difficulty resulting from offenders' subserviently refusing to undergo consensual criminal neurorehabilitation. ${ }^{22}$ Yet, for the sake of simplicity, below I continue with the example of subservience.

\section{Three Possible Objections}

In view of the above considerations, criticizing nonconsensual criminal neurorehabilitation for expressing a degrading attitude towards offenders appears incompatible with simultaneously endorsing consensual criminal neurorehabilitation. Yet, the above considerations for that conclusion could be deemed misguided. Below, I assess three possible criticisms that readily suggest themselves. The criticisms relate to the degradingness of subservient

\footnotetext{
${ }^{21}$ As proposed, criminal neurorehabilitation plausibly could also help with such things as negative employment prospects, economic difficulties, and substance abuse that, like subservience, are likely to make a criminal life demeaning.

${ }^{22}$ How general the problem would actually be is an empirical question the correct answer to which can plausibly vary from time and jurisdiction to another. Yet, it appears safe to say that the problem would be common enough for the argument not to be dismissible by maintaining that anything can be shown to be morally (un)problematic by embedding it in a sufficiently fantastic context.
}

nonconsensual criminal neurorehabilitation as compared to that of subservient consensual criminal neurorehabilitation, to the relationship between degradingness and moral permissibility, and to the conception of autonomy presupposed by the above considerations, respectively.

\section{Subservient Nonconsensual Criminal Neurorehabilitation Would Convey a more Degrading Attitude towards Offenders than its Consensual Counterpart}

The above considerations are based on a comparison between an offender who out of her subservience refuses the criminal neurorehabilitation proposed to her and a subservient offender who is subjected to nonconsensual criminal neurorehabilitation. Someone might now argue that, instead of comparing an offender who subserviently refuses criminal neurorehabilitation with a subservient offender neurorehabilitated independently of his will, we should compare the latter with an offender who subserviently consents to undergo criminal neurorehabilitation. And the degradingness occurring in the case of a subservient offender who undergoes nonconsensual criminal neurorehabilitation would, the objection could continue, apparently be worse than that exemplified by an offender who subserviently undergoes consensual criminal neurorehabilitation. In view of this, the critic could conclude, nonconsensual criminal neurorehabilitation would express a more degrading attitude towards offenders than consensual criminal neurorehabilitation, the above considerations notwithstanding.

However, as attested to by the cases of Anna, Charles, Diana, and Ethan, that one consents to degrading treatment does not mean that the treatment thereby ceases to be degrading. And consensual criminal neurorehabilitation too would do such things as alter offenders' mental machinery at the neurophysiological level. ${ }^{23}$ To the extent that such things would express a degrading attitude towards offenders, as they are now assumed to do to some significant degree, consensual neurocorrectives too would convey a degrading attitude towards offenders. It might be taken that consensual criminal neurorehabilitation would nevertheless express

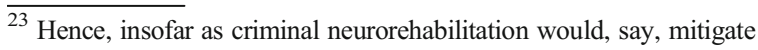
an offender's motivation to harm others by altering her neurophysiology, the result would not be based on her critically assessing the reasons behind her being motivated to harm others, were the rehabilitation consensual or not.
} 
a less degrading attitude towards offenders than its nonconsensual counterpart, because the former would allow an offender autonomously to choose whether or not she undergoes the degradingness in question whereas the latter would not.

Yet, as the possible objection now being considered asks us to do, we are now focusing on an offender whose choice to undergo criminal neurorehabilitation results from her subservience. As her subservience is quite demeaning, allowing an offender's choice about rehabilitation to have such a basis would not appear to express a less degrading attitude towards her than not deeming her choice relevant to warranting her criminal neurorehabilitation would convey. Indeed, the opposite view would apparently presuppose that just allowing a person some kind of choice as regards given treatment amounts to expressing a less degrading attitude towards her than treating her in a similar way without giving her the possibility to choose. However, intuitively plausibly, for instance, a robber who says to his victim 'Your money or your life' treats her at least as degradingly as does an otherwise similar robber who just takes his victim's money without giving her such a possibility to choose. Although being robbed and being subservient are evidently not the same, from the viewpoint of degradingness they would appear to be similar to each other here.

Moreover, to be as practically relevant as possible, an assessment of the degradingness of the attitude that consensual and nonconsensual criminal neurorehabilitation would convey towards offenders should pay heed to the conditions in which the practices would be applied. And such assessment should also duly acknowledge the possible consequences of the fact that consensual rehabilitation also allows offenders to refuse to be rehabilitated. ${ }^{24}$ Had Ethan been allowed to decide about it, like Diana, he

\footnotetext{
${ }^{24}$ Unlike the comparison between a subservient offender subjected to nonconsensual criminal neurorehabilitation and an offender who subserviently consents to undergo criminal neurorehabilitation just focused on above, the comparison between Ethan and Diana acknowledges the possible consequences of the fact that consensual rehabilitation also allows offenders to refuse to be rehabilitated. The former comparison is relevant here in that it draws attention to the degradingness related to the cases of offenders who would subserviently consent to undergo criminal neurorehabilitation. An overall assessment of the degradingness of the attitude that consensual and nonconsensual criminal neurorehabilitation would convey towards offenders should acknowledge that degradingness too. Yet, as that degradingness relates to consensual criminal neurorehabilitation, acknowledging it rather speaks against the view that nonconsensual criminal neurorehabilitation expresses a more degrading attitude towards offenders than consensual criminal neurorehabilitation than for it.
}

would, it is now assumed, have refused to undergo criminal rehabilitation. Hence, allowing only consensual criminal neurorehabilitation would preclude cases such as Ethan's, in which nonconsensual neurocorrectives would help an offender to leave behind his degrading existence. Accordingly, by prohibiting nonconsensual criminal neurorehabilitation, a criminal justice system would convey that it does not care as much about whether or not such offenders lead a degrading criminal existence as does a criminal justice system that allows nonconsensual criminal neurorehabilitation. Given a sufficient number of offenders like Ethan, consensual criminal neurorehabilitation could then express an even more degrading attitude towards offenders than its nonconsensual counterpart would convey, even if things were different in the abstract (which in view of the remarks of the above passages they would not appear to be). Of course, whether offenders like Ethan would exist in such a number could plausibly vary with time and place. But that we here end up with this kind of contingent, empirical matter shows that, even though only consensual criminal neurorehabilitation would allow offenders to choose whether to undergo the degradingness criminal neurorehabilitation would involve, nonconsensual neurorehabilitation would not necessarily express a more degrading attitude towards offenders than would its consensual counterpart.

Consensual Degradingness Can Be Morally Permissible

It is commonly accepted that a medical procedure that involves something ordinarily considered degrading can be morally permissible when a patient autonomously consents to undergo the procedure (see e.g. [50]). Correspondingly, it could here be taken that by autonomously consenting to the degradingness that criminal neurorehabilitation would express towards her an offender could make the degradingness morally permissible in her case. As the degradingness conveyed by nonconsensual criminal neurorehabilitation would be independent of the consent of the offenders subjected to it, nonconsensual criminal neurorehabilitation would apparently be importantly different. Accordingly, the conclusion of this possible criticism could be, consensual criminal neurorehabilitation would still be morally more justifiable than nonconsensual criminal neurorehabilitation, the above considerations notwithstanding. 
However, whether or not its analogy between a patient and an offender is otherwise plausible, this possible objection would not duly account for the moral concern raised by the subservience of offenders such as Diana, who submissively refuse to undergo criminal neurorehabilitation. ${ }^{25}$ Some authors do maintain that the subservience of a person like Anna - to return to the case of the subservient wife described above - need not be morally questionable insofar as it is guided by critical evaluation in accord with her own principles (see e.g. [51]). Yet, the moral concern that Diana's subservience causes, at least, rationally cannot be dealt with just by referring to the consensual nature of her submissiveness. After all, because of her subservience, Diana continues to live a degrading life of submissiveness, violence, and crime, which can cause even significant harm to other people too. Accordingly, the view that her consenting to it makes Diana's subservience morally acceptable should be complemented with a plausible account of how her consent could have that kind of moral significance. ${ }^{26}$ In the absence of such an account, this possible objection is implausible.

\section{The Conception of Autonomy Should Be Replaced with a more Stringent One}

As offenders like Diana can meet the criteria of autonomy commonly employed in connection with criminal rehabilitation, nonconsensual criminal neurorehabilitation need not, I proposed, express a more degrading attitude towards offenders than consensual criminal neurorehabilitation. It could be taken that this result could be easily avoided just by reformulating the criteria of autonomy used in this context in a way that precludes the kind of subservience Diana exemplifies. Once the notions of consensual and nonconsensual would be interpreted accordingly, the possible objection could proceed, nonconsensual criminal neurorehabilitation would express a more degrading attitude towards offenders than its consensual counterpart.

\footnotetext{
$\overline{25}$ That the analogy between a patient and an offender would be otherwise plausible is not clear. For instance, the conditions under which a patient consents to a medically indicated treatment could differ from those under which an offender consents to criminal neurorehabilitation in a sense relevant here (see also e.g. [24]). For the sake of argument, I now put this complication aside.

${ }^{26}$ Given the differences between the contexts, it is also not clear how relevant the considerations for thinking that women's deference to oppressive patriarchal norms can be morally acceptable would be in Diana's case. And, of course, whether such considerations are acceptable remains debated (see e.g. [52]).
}

Hence, the criticism of nonconsensual criminal neurorehabilitation focused on here could ultimately be correct after all.

If the requirements of autonomy employed here were replaced with criteria that precludes the subservience Diana exemplifies, cases of offenders like her would not show that nonconsensual criminal neurorehabilitation need not express a more degrading attitude towards offenders than its consensual counterpart. However, the more stringent the requirements of autonomy employed here would be, the fewer offenders would be eligible for consensual criminal rehabilitation. ${ }^{27}$ And if only offenders who meet the more stringent criteria of autonomy could be rehabilitated, offenders relevantly similar to Ethan and Diana would assumedly continue to lead their degrading criminal existence. ${ }^{28}$ By allowing the offenders to continue to lead such an existence, a criminal justice system would convey that it does not care as much about whether or not they lead a degrading criminal existence as does a criminal justice system that permits nonconsensual criminal neurorehabilitation. Hence, the overall outcome of adopting the more stringent criteria of autonomy could be that of ending up expressing an even more degrading attitude towards offenders than would have been conveyed by employing the laxer criteria of autonomy and permitting nonconsensual criminal neurorehabilitation.

True, whether adopting the more stringent criteria of autonomy would actually result in expressing a more degrading attitude towards offenders depends on contingent empirical matters, such as how many offenders would satisfy the more demanding criteria of autonomy and how many of those who would not meet it would lead a degrading existence. Yet, that we, again, end up

\footnotetext{
${ }^{27}$ Responding that the criteria for autonomously refusing to undergo criminal neurorehabilitation should be more stringent than the criteria for autonomously consenting to undergo criminal neurorehabilitation would not appear to amount to more than an ad hoc maneuver here.

${ }^{28}$ Maintaining that offenders who do not meet the criteria of autonomy could be rehabilitated independently of their will would presuppose endorsing nonconsensual criminal rehabilitation. Given that such more traditional methods of criminal rehabilitation as, say, cognitive behavioral therapy would be unlikely to work in the cases of offenders unwilling to be rehabilitated, rehabilitation of unwilling offenders would assumedly need to employ neurocorrectives (that alter offenders' mental life at the neurophysiological level alone). Hence, rehabilitating offenders who would not satisfy the more stringent criteria of autonomy would apparently presuppose endorsing nonconsensual criminal neurorehabilitation. Although proponents of the criticism of nonconsensual criminal neurorehabilitation now assessed need not consider their criticism decisive, this option would assumedly be unappealing to them.
} 
with matters that can vary from time and place to another suffices to show that nonconsensual criminal neurorehabilitation would not necessarily express a more degrading attitude towards offenders than its consensual counterpart, even if the conception of autonomy employed in this context were replaced with one that precludes the kind of subservience on which the argument of this article focuses.

\section{Conclusion}

In this article, I have assessed a criticism of nonconsensual criminal neurorehabilitation according to which such rehabilitation would convey a degrading attitude towards offenders. By using cases of persons who lead a subservient existence as an example, I maintained that nonconsensual criminal neurorehabilitation need not express a more degrading attitude towards offenders than consensual criminal neurorehabilitation. The questions of degradingness focused on above are not the only questions relevant to determining the moral or legal acceptability of nonconsensual criminal neurorehabilitation. Hence, as proposed, the argument of this article does not show that nonconsensual criminal neurorehabilitation is morally or legally acceptable. But, insofar as the argument is plausible, criticizing nonconsensual criminal neurorehabilitation for expressing a degrading attitude towards offenders is not compatible with simultaneously endorsing consensual criminal neurorehabilitation.

Accordingly, to the extent that the moral and legal acceptability of permitting criminal neurorehabilitation depends on whether such rehabilitation expresses a degrading attitude towards offenders, nonconsensual criminal neurorehabilitation ought not to be considered necessarily less permissible than its consensual counterpart. And insofar as consensual criminal neurorehabilitation is seen as a potentially acceptable way of rehabilitating offenders, nonconsensual criminal neurorehabilitation consistently ought not to be ruled out for expressing an unacceptably degrading attitude towards offenders. Finally, an offender's choice about undergoing criminal rehabilitation can involve the kinds of degradingness talked about above whether or not the rehabilitation would employ neuroscientific means. Consequently, the considerations presented above can also be of relevance in assessing the moral and legal acceptability of criminal rehabilitation that uses other than neuroscientific means.
Acknowledgments I thank two anonymous reviewers of this journal for helpful comments and the ERA-NET Neuron and the Academy of Finland (grant number 318954) for financial support.

Funding Open access funding provided by University of Turku (UTU) including Turku University Central Hospital.

Open Access This article is licensed under a Creative Commons Attribution 4.0 International License, which permits use, sharing, adaptation, distribution and reproduction in any medium or format, as long as you give appropriate credit to the original author(s) and the source, provide a link to the Creative Commons licence, and indicate if changes were made. The images or other third party material in this article are included in the article's Creative Commons licence, unless indicated otherwise in a credit line to the material. If material is not included in the article's Creative Commons licence and your intended use is not permitted by statutory regulation or exceeds the permitted use, you will need to obtain permission directly from the copyright holder. To view a copy of this licence, visit http://creativecommons.org/licenses/by/4.0/.

\section{References}

1. Birks, David, and Thomas Douglas. 2018. Treatment for crime: Philosophical essays on neurointerventions in criminal justice. Oxford: Oxford University Press.

2. de Kogel, Catharina H. 2019. More autonomous or more fenced-in? Neuroscientific instruments and intervention in criminal justice. Neuroethics 12: 243-254.

3. Ryberg, Jesper. 2020. Neurointerventions, crime, and punishment: Ethical considerations. New York: Oxford University Press.

4. Shniderman, Adam B., and Lauren B. Solberg. 2015. Cosmetic psychopharmacology for prisoners: Reducing crime and recidivism through cognitive intervention. Neuroethics 8: 315-326.

5. Matravers, Matt. 2018. The importance of context in thinking about crime-preventing neurointerventions. In Treatment for crime: Philosophical essays on neurointerventions in criminal justice, ed. David Birks and Thomas Douglas, 71-93. Oxford: Oxford University Press.

6. Pugh, Jonathan, and Hannah Maslen. 2017. 'Drugs that make you feel bad'? Remorse-based mitigation and neurointerventions. Criminal Law and Philosophy 11: 499-522.

7. Bomann-Larsen, Lene. 2013. Voluntary rehabilitation? On neurotechnological behavioural treatment, valid consent and (in)appropriate offers. Neuroethics 6: 65-77.

8. Bublitz, Jan Cristoph. 2018. 'The soul is the prison of the body': Mandatory moral enhancement, punishment, and rights against neurorehabilitation. In Treatment for crime: Philosophical essays on neurointerventions in criminal justice, ed. David Birks and Thomas Douglas, 289-320. Oxford: Oxford University Press.

9. Kirchmair, Lando. 2019. Objections to coercive neurocorrectives for criminal offenders - Why offenders' human rights should fundamentally come first. Criminal Justice Ethics 38 (1): 19-40. 
10. Shaw, Elizabeth. 2018. Against the mandatory use of neurointerventions in criminal sentencing. In Treatment for crime: Philosophical essays on neurointerventions in criminal justice, ed. David Birks and Thomas Douglas, 321-337. Oxford: Oxford University Press.

11. Douglas, Thomas. 2019. Nonconsensual neurocorrectives and bodily integrity: A reply to Shaw and Barn. Neuroethics 12: 107-118.

12. Douglas, Thomas. 2014. Criminal rehabilitation through medical intervention: Moral liability and the right to bodily integrity. The Journal of Ethics 18: 101-122.

13. Theofilopoulou, Areti. 2019. Punishment as moral fortification and non-consensual neurointerventions. Law and Philosophy 38 (2): 149-167.

14. Code of Laws of the United States of America. $\S 3582$. Imposition of a sentence of imprisonment. https://www. law.cornell.edu/uscode/text/18/3582\#a, accessed June 18, 2020.

15. European Court of Human Rights. 2013. Case of Vinter and others v. The United Kingdom. https://hudoc.echr.coe. int/eng\#\{\%22itemid\%22:[\%22001-122664\%22]\}, accessed June 18, 2020.

16. European Court of Human Rights. 2014. Case of Harakchiev and Tolumov v. Bulgaria. https://hudoc.echr. coe.int/eng\#\{\%22itemid\%22:[\%22001-145442\%22]\}, accessed June 18, 2020.

17. Meijer, Sonja. 2017. Rehabilitation as a positive obligation. European Journal of Crime, Criminal Law and Criminal Justice 25: 145-162.

18. Ryberg, Jesper. 2015. Is coercive treatment of offenders morally acceptable? On the deficiency of the debate. Criminal Law and Philosophy 9: 619-631.

19. Simourd, David J., Mark E. Olver, and Bryan Brandenburg. 2016. Changing criminal attitudes among incarcerated offenders: Initial examination of a structured treatment program. International Journal of Offender Therapy and Comparative Criminology 60: 1425-1445.

20. Jwa, Anita S. 2019. Regulating the use of cognitive enhancement: An analytic framework. Neuroethics. 12: 293-309. https://doi.org/10.1007/s12152-019-09408-5.

21. Sandberg, Anders, Walter Sinnott-Armstrong, and Julian Savulescu. 2011. Cognitive enhancement in courts. In Oxford handbook of neuroethics, ed. Judy Illes and Barbara J. Sahakian, 273-284. New York: Oxford University Press.

22. Schleim, Stephan, and Boris B. Quednow. 2018. How realistic are the scientific assumptions of the neuroenhancement debate? Assessing the pharmacological optimism and neuroenhancement prevalence hypotheses. Frontiers in Pharmacology 9: 1-7.

23. Conan, Gregory Mark. 2020. Frequently overlooked realistic moral bioenhancement interventions. Journal of Medical Ethics 46: 43-47.

24. Pugh, Jonathan. 2018. Coercion and the neurocorrective offer. In Treatment for crime: Philosophical essays on neurointerventions in criminal justice, ed. David Birks and Thomas Douglas, 94-114. Oxford: Oxford University Press.

25. Vallentyne, Peter. 2018. Neurointerventions, self-ownership, and enforcement rights. In Treatment for crime: Philosophical essays on neurointerventions in criminal justice, ed. David Birks and Thomas Douglas, 124-139. Oxford: Oxford University Press.

26. Martin, Wayne, and Sándor Gurbai. 2019. Surveying the Geneva impasse: Coercive care and human rights. International Journal of Law and Psychiatry 64: 117-128.

27. Garnett, Michael. 2014. The autonomous life: A pure social view. Australasian Journal of Philosophy 92: 143-158.

28. Korsgaard, Christine M. 2009. Self-constitution. Oxford: Oxford University Press.

29. Council of Europe. 1950. European convention of human rights. https://www.echr.coe.int/Pages/home.aspx? $\mathrm{p}=$ basictexts. Accessed June 18, 2020.

30. Hill, Thomas E. 1973. Servility and self-respect. Monist 57 (10): 87-104.

31. Schaber, Peter. 2020. The volenti maxim. The Journal of Ethics 24: 79-89.

32. Hills, Alison. 2003. Duties and duties to the self. American Philosophical Quarterly 40: 131-142.

33. Schofield, Paul. 2015. On the existence of duties to the self and their significance for moral philosophy. Philosophy and Phenomenological Research 90: 505-528.

34. Schaab, Janis David. 2020. On the supposed incoherence of obligations to oneself. Australasian Journal of Philosophy: 1-15. https://doi.org/10.1080/00048402.2020.1714677.

35. Cibik, Matej. 2020. On the immorality of tattoos. The Journal of Ethics 24: 193-206. https://doi.org/10.1007 /s10892-019-09319-w.

36. Cholbi, Michael. 2017. Paternalism and our rational powers. Mind 126 (501): 123-153.

37. Groll, Daniel. 2019. Paternalism, disagreements, and the moral difference. American Philosophical Quarterly 56 (1): 57-70.

38. Rocha, James. 2011. Autonomy within subservient careers. Ethical Theory and Moral Practice 14 (3): 313-328.

39. Rawls, John. 2009. A theory of justice. Revised edition. Cambridge: Harvard University Press.

40. Woollard, Fiona, and Howard-Snyder, Frances. 2016. Doing vs. allowing harm. The Stanford encyclopedia of philosophy (winter 2016 edition), ed. Edward N. Zalta. https://plato. stanford.edu/entries/doing-allowing/. Accessed June 18, 2020.

41. Cale, Jesse, Darryl Plecas, Irwin M. Cohen, and Stephanie Fortier. 2010. An exploratory analysis of factors associated with repeat homicide in Canada. Homicide Studies 14 (2): 159-180.

42. Koppen van, Vere M., Christianne J. de Poot, and Arjan A.J. Blokland. 2010. Comparing criminal careers of organized crime offenders and general offenders. European Journal of Criminology 7 (5): 356-374.

43. Pari, Anees Ahmed Abdul, Emma Plugge, Sarah Holland, Janet Maxwell, and Premila Webster. 2012. Health and wellbeing of offenders on probation in England: An exploratory study. The Lancet 380 : S21-S21.

44. Pizarro, Jesenia M., Kristen M. Zgoba, and Wesley G. Jennings. 2011. Assessing the interaction between offender and victim criminal lifestyles \& homicide type. Journal of Criminal Justice 39: 367-377.

45. Ronel, Natti. 2011. Criminal behavior, criminal mind: Being caught in a "criminal spin". International Journal of Offender Therapy and Comparative Criminology 55 (8): 1208-1233. 
46. Kollar, Eszter, and Daniele Santoro. 2012. Not by bread alone: Inequality, relative deprivation, and self-respect. Philosophical Topics 40 (1): 79-96.

47. Schemmel, Christian. 2019. Real self-respect and its social bases. Canadian Journal of Philosophy 49 (5): 628-651.

48. Soest, Von, Jenny Wagner Tilmann, Thomas Hansen, and Denis Gerstorf. 2018. Self-esteem across the second half of life: The role of socioeconomic status, physical health, social relationships, and personality factors. Journal of Personality and Social Psychology 114 (6): 945-958.

49. Bonanno, Joseph. 2003. A man of honor: The autobiography of Joseph Bonanno. New York: St. Martin's Press.
50. Beauchamp, Tom L., and James F. Childress. 2013. Principles of biomedical ethics. 7th ed. New York: Oxford University Press.

51. Friedman, Marilyn. 1985. Moral integrity and the deferential wife. Philosophical Studies 47 (1): 141-150.

52. MacKay, Kathryn. 2019. Authenticity and normative authority: Addressing the agency dilemma with values of one's own. Journal of Social Philosophy, forthcoming.

Publisher's Note Springer Nature remains neutral with regard to jurisdictional claims in published maps and institutional affiliations. 